\title{
Description and Comparison of Acute Pain Characteristics After Laparoscope-Assisted Vaginal Hysterectomy, Laparoscopic Myomectomy and Laparoscopic Adnexectomy
}

\author{
Sijia Chen ${ }^{1} * *$ \\ Wenwen $\mathrm{Du}^{\mathrm{l}}$,* \\ Xiuxiu Zhuang $\mathbb{D}^{1, *}$ \\ Qinxue Dai (D) ${ }^{\prime}$ \\ Jingwen $\mathrm{Zhu}^{2}$ \\ Haifeng Fu' \\ Junlu Wang' \\ Luping Huang'
}

'Department of Anesthesiology, The First Affiliated Hospital of Wenzhou Medical University, Wenzhou, People's Republic of China; ${ }^{2}$ Wenzhou Medical University, Wenzhou, People's Republic of China

*These authors contributed equally to this work
Correspondence: Luping Huang Departments of Anesthesiology, The First Affiliated Hospital of Wenzhou Medical University, Wenzhou, Zhejiang, People's Republic of China

Tel +86 I358789|399

Fax +86 577-55578999-689854

Email csj0122@wmu.edu.cn
Purpose: To determine the characteristics of the acute pain after laparoscopic-assisted vaginal hysterectomy (LAVH), laparoscopic myomectomy (LM), and laparoscopic adnexectomy (LA) and compare them with each other.

Patients and Methods: Patients undergoing LAVH, LM, and LA under general anaesthesia at the First Affiliated Hospital of Wenzhou Medical University between December 2017 and December 2019 were selected. Their data were collected before, during, and after the surgery. We evaluated the degrees of pain in each group of patients and compared them.

Results: There were differences in the baseline characteristics of the patients in the LAVH, LM, and LA groups. The severity and incidence of postoperative pain were higher in the LAVH group than in the LM and LA groups, followed by the LM and LA groups. Compared with the LA group, the postoperative pain in the LAVH and LM groups was more complicated. The LA group had the lowest incidence of two or more types of moderate to severe pain. The LAVH and LM groups mainly had visceral pain and low back pain, and the LA group mainly had incisional pain. Shoulder pain had the lowest incidence in the three groups. Conclusion: There were different postoperative pain characteristics after the LAVH, LM, and LA, and we should clinically adjust analgesia programs for different gynaecological laparoscopic surgeries.

Keywords: postoperative pain, laparoscope-assisted vaginal hysterectomy, laparoscopic myomectomy, laparoscopic adnexectomy

\section{Introduction}

Acute postoperative pain was one of the most common problems after surgery, which delayed the healing process, increased postoperative complications and mortality, increased the duration of hospitalisation and nursing costs. ${ }^{1}$ Although gynecological laparoscopic surgery was considered less traumatic, it also had several postoperative troubles. ${ }^{2,3}$

Previous studies have shown that postoperative acute pain was more likely to occur in female patients. ${ }^{4,5}$ Gynaecological laparoscopic surgery was associated with mild postoperative pain, but the incidence of postoperative pain was relatively high. One of the possibilities for this difference was that the population comprised only female patients with high pain sensitivity. ${ }^{6-8}$ At the same time, several studies have suggested that pain control after gynaecological laparoscopic surgery was 
poor. $^{9}$ In addition, different treatment approaches produced different pain relief effects. ${ }^{10}$ Previous studies have investigated the characteristics of acute pain after total laparoscopic hysterectomy (TLH) and laparoscopicassisted vaginal hysterectomy (LAVH). ${ }^{11,12}$ Nowadays, gynaecological laparoscopic surgery also involves laparoscopic myomectomy (LM) and laparoscopic adnexectomy (LA).

To solve the unsatisfactory postoperative analgesia, we should first understand the characteristics of postoperative pain, such as the nature, location, intensity and duration. This study focused on the demographic baseline characteristics and the preoperative and postoperative characteristics of patients undergoing LAVH, LM, and LA and use them to compare the pain characteristics associated with different laparoscopic gynaecological surgeries.

\section{Methods}

\section{Study Design and Participant Recruitment}

This study selected patients who underwent LAVH, LM, and LA under general anaesthesia between December 2017 and December 2019 at the First Affiliated Hospital of Wenzhou Medical University. Written informed consent was obtained from every participant through a preoperative interview. The data of 669 patients were finally analysed, including those of 249 patients in the LAVH group, 210 patients in the LM group, and 210 patients in the LA group. This prospective observational cohort study was approved by the Ethics Committee (2019-030) for Clinical Research for the First Affiliated Hospital of Wenzhou Medical University and conducted in accordance with the Declaration of Helsinki. The study was registered in the China Clinical Trial Registry: ChiCTR-ROC -17013036. The exclusion criteria were as follows: ASA of $\geq 3$, age of $<19$ years, malignant lesions, previous severe cardiopulmonary disease, liver and kidney dysfunction, history of mental illness, pregnant or breastfeeding women, language, and self-expression disorders.

\section{Types of Outcomes}

In this study, the numerical rating scale (NRS) was used to evaluate the intensity of pain. The pain scores ranged from 0 to 10 . Based on the pain scores, the pain intensities were categorized into four: no pain (NRS is 0 ), mild pain (NRS is 1 to 3 ), moderate pain (NRS is 4 to 6 ), and severe pain (NRS is 7 to 10$){ }^{13}$
Previous studies have reported that the components of various forms of postoperative pain are as follows: incisional pain: pain on the surface of the wound or abdominal surface that people can "touch"; visceral pain: pain that may be deep and difficult to locate and is mainly in the lower abdomen; low back pain: pain between the 12th rib and lower gluteal muscles with or without leg pain; shoulder pain: pain in the shoulder.

\section{Data Collection}

The preoperative variables of the patients included age, body mass index (BMI), level of education, occupation, exercise habits, individual medical history, obstetric history, previous surgery history, preoperative chronic pain history, medical insurance type, main indication for surgery, and level of anxiety. These data were obtained and entered the day before the surgery. Pelvic adhesion is a preoperative factor found during surgery; we classified it as a preoperative factor, as it existed before the surgery. The intraoperative variables included the number of trocars, intraoperative diagnosis, duration of surgery, blood loss, and intraoperative complications. The postoperative variables included postoperative nausea and vomiting, pelvic drainage time, indwelling catheter time, and 24-h pelvic drainage; they were collected and entered after surgery.

\section{Anesthesia, Surgical Procedures and Analgesia}

In this study, two anaesthesiologists performed anaesthesia and analgesia for LAVH, LM, and LA, referring to the 2017 version of the expert consensus and the previous perioperative analgesia records. No preoperative analgesics were administered before the three types of laparoscopic surgery.

\section{Anesthesia, Surgery and Analgesia of LAVH}

After the patient entered the room, the anaesthesiologist checked the name and information and conducted routine assessments and monitoring, such as electrocardiogram (ECG), non-invasive blood pressure (NIBP), and noninvasive pulse oxygen saturation ( $\mathrm{SpO} 2)$. The bispectral index (BIS) was used to monitor the depth of anaesthesia in patients. Sufentanil $(0.4 \mu \mathrm{g} / \mathrm{kg})$, propofol $(2-3 \mathrm{mg} / \mathrm{kg})$, and rocuronium $(0.6-0.8 \mathrm{mg} / \mathrm{kg})$ were used to induce anaesthesia as intravenous boli. Tracheal intubation was performed $90 \mathrm{~s}$ after the bolus injection of rocuronium. After intubation, the IPAP ventilation mode, tidal volume (6-8 $\mathrm{mL} / \mathrm{kg}), \mathrm{RR}$ (12 times/min), inspiratory-expiratory 
ratio $(\mathrm{I} / \mathrm{E}=1 / 2)$, and an oxygen/air ratio of $1: 2$ were used. The depth of anesthesia was maintained with $3 \mathrm{mg} / \mathrm{kg} / \mathrm{h}$ propofol, $0.1-0.3 \mu \mathrm{g} / \mathrm{kg} / \mathrm{min}$ remifentanil and $1.0-2.5 \%$ sevoflurane after intubation and the BIS value was maintained between 40 and 60 . All surgeries were performed or supervised by experienced gynaecologists according to the standardised LAVH protocol, which involves the use of one $10-\mathrm{mm}$ and two or three $5-\mathrm{mm}$ laparoscopic trocars to remove the uterus through the vagina. Intra-abdominal pressure was maintained at $12-13 \mathrm{~mm} \mathrm{Hg}$ during the surgery. After the laparoscopic surgery, the abdomen was manually pressed, and the laparoscopic trocar was opened to empty the $\mathrm{CO} 2$. Morphine $(0.1 \mathrm{mg} / \mathrm{kg}$ iv) was administered to prevent postoperative pain, and palonosetron (0.25 mg iv) was administered to prevent nausea and vomiting. The use of inhaled anaesthetics was discontinued. After suturing the skin, the surgeon used $10 \mathrm{~mL}$ of ropivacaine at a concentration of $0.75 \%$ to perform local infiltration anaesthesia at the incision site. After the operation was finished, the infusion of remifentanil and propofol was stopped. In the PACU, the anaesthesiologist titrated the patient with intravenous morphine, asked about pain intensity every 5 minutes, and administered a dose of 1$2 \mathrm{mg}$ of morphine (NRS $\geq 4$ points) until sufficient analgesia was achieved (NRS $<4$ points). After $1 \mathrm{~h}$, the patient left the PACU and was sent to the ward. In the ward, when the patient's postoperative NRS for pain was $\geq 4,50 \mathrm{mg}$ of indomethacin suppository was administered. If the postoperative pain persisted with NRS of $\geq 4$, intramuscular pethidine was injected to relieve pain.

The researcher who was blinded to patients undergoing surgery performed the postoperative pain assessment. $\mathrm{He}$ went to the ward to follow up on the patients on the first day and at 17:00 on the second day after the surgery, and he retrospectively assessed and recorded the patient's pain. ${ }^{14}$ The NRS score was used to evaluate the acute postoperative pain and its components. According to previous studies, the first day after surgery was the day on which the highest pain intensity score was recorded. ${ }^{11}$ Therefore, this study used the maximum pain score within 2 days as the postoperative severity pain score. ${ }^{15}$

\section{Anesthesia, Surgery and Analgesia of LM}

All surgeries were performed or supervised by experienced gynaecologists according to the LM standardisation plan, which involves the use of one $10-\mathrm{mm}$ and two or three 5-mm laparoscopic trocars to remove uterine fibroids through laparoscopy. The rest of the process was the same as that of LAVH.

\section{Anesthesia, Surgery and Analgesia for LA}

All surgeries were performed or supervised by experienced gynaecologists in accordance with the LA standardised protocol, which involves the use of one 10-mm and two or three 5-mm laparoscopic trocars to remove the ovaries through laparoscopy. After the surgery, the patients did not receive routine morphine analgesia, but were administered nonsteroidal anti-inflammatory drugs (NSAIDs) for analgesia. The rest of the process was the same as that of LAVH.

\section{Statistical Analysis}

Stata 15 was used for the statistical analysis. The baseline data were summarised using mean \pm standard deviation if they were normally distributed and the variances were uniform; otherwise, the median (quartile) was used, and the counting data were represented by the component ratio or rate. The Kolmogorov-Smirnov test was used to determine normality. Box or scatter plots were used to demonstrate the outliers. The chi-squared test was used to compare the measurement data of the groups. Bonferroni test was used for multiple comparisons. All statistical tests were two-sided, and statistical significance was set at $\mathrm{P}<0.05$.

\section{Results}

A total of 823 patients were enrolled in the study. Finally, the data of the 669 patients were used for the final statistical analysis; these data included those for 249, 210, and 210 patients in the LAVH, LM, and LA groups, respectively (Figure 1).

As shown in Table 1, there were significant differences between the preoperative baseline characteristics of the patients in the LAVH, LM, and LA groups, such as age, BMI, anxiety, education, chronic pain before surgery, occupation, medical insurance type, diabetes history, history of blood pressure, parity, history of dysmenorrhea, chief complaint, and pelvic adhesions. There were also significant differences in the number of trocars during the surgery and the duration of the surgery. There were significant differences in the duration of the postoperative pelvic drainage, indwelling catheter time, and the 24 $\mathrm{h}$ pelvic drainage volumes of the three groups (Table 1).

Visceral pain had the highest incidence and was most severe in the LAVH group (Tables 2 and 3), followed by low back pain; moderate incision pain was milder than low back 


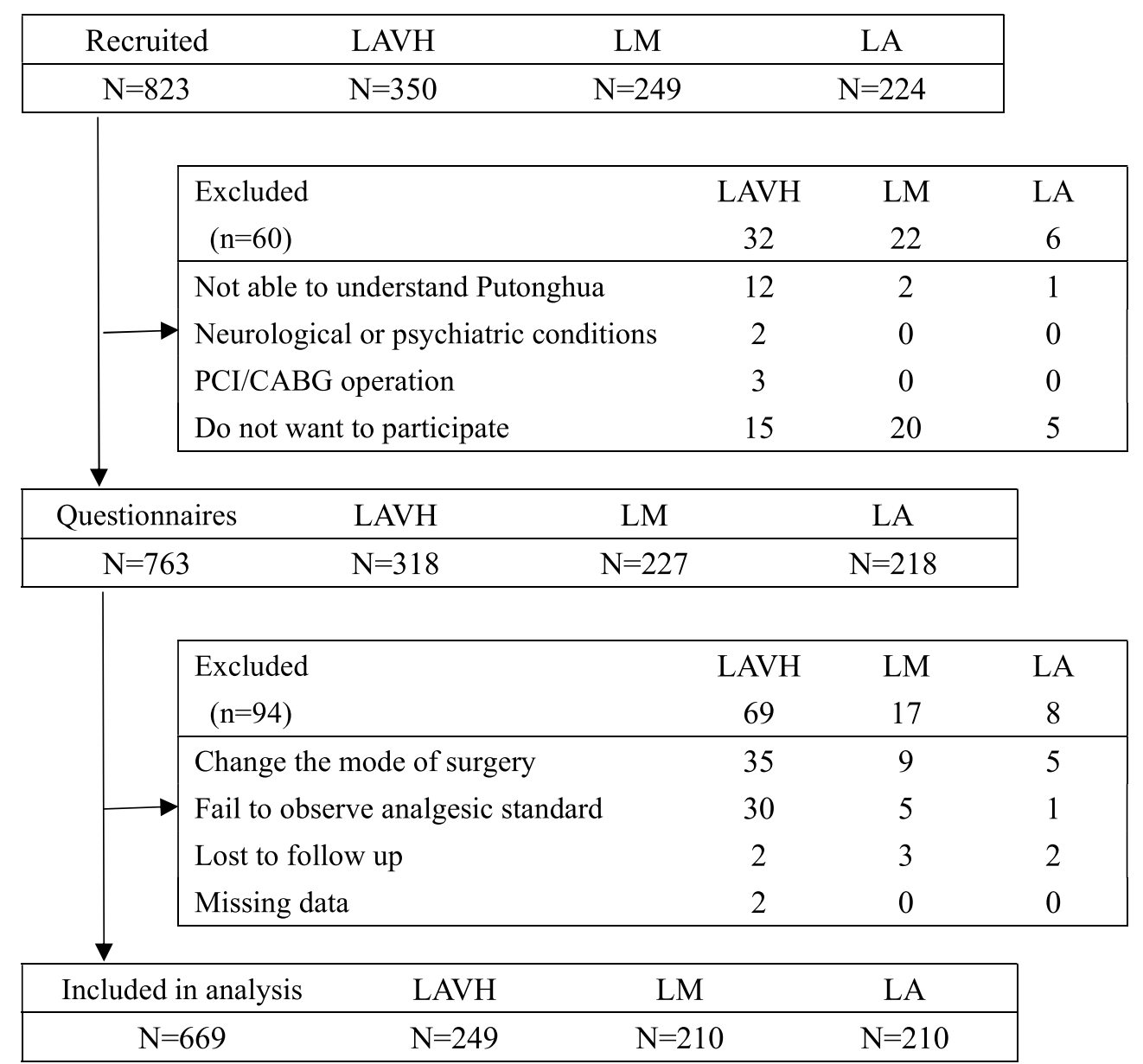

Figure I Recruitment flowchart, showing numbers of patients recruited by type of surgery and those lost up until the times of the follow-up visit in the first and second days.

Abbreviations: LAVH, laparoscope-assisted vaginal hysterectomy; LM, laparoscopic myomectomy; LA, laparoscopic adnexectomy.

pain and shoulder pain was the mildest in the LAVH group. Up to $73.1 \%$ of patients in the LAVH group had one or more types of moderate to severe pain (Tables 2 and 3).

Visceral pain had the highest incidence and was the most severe in the LM group (Tables 4 and 5), followed by low back pain; moderate and severe incision pain were relatively milder than low back pain; shoulder pain was the mildest in the LM group. Of the patients in the LM group, $61.0 \%$ had one or more forms of moderate to severe pain (Tables 4 and 5).

As shown in Tables 6 and 7, the acute postoperative pain in the LA group was mainly incisional pain, followed by visceral pain and low back pain; shoulder pain was the mildest. In the LA group, as many as $39.0 \%$ of patients had one or more types of moderate to severe pain, but none had four types of moderate to severe pain (Tables 6 and 7).

The LAVH group had the most severe pain, followed by the LM group and the LA group. The consumption of opioids in the operating room was higher for the LAVH group than for the LA group but was not significantly different from that for the LM group; there was no significant difference between the LM and LA groups. There was no significant difference in the number of opioid users in the PACU among the three groups. In the ward, the LAVH group had the most users of indomethacin and pethidine, followed by the LA group; the LM group had the least number of users. The total consumption of opioids was highest in the LAVH group and significantly different from that for the LA group but not from that for the LM group, and there was no significant difference between LA and LM (Table 8).

\section{Discussion}

In this study, there were significant differences in the baseline characteristics of patients in the LAVH, LM, and LA groups, and age, obesity, anxiety, education level, chronic pain, occupation, and other preoperative 
Table I Demographic and Patient Characteristics for Laparoscope-Assisted Vaginal Hysterectomy, Laparoscopic Myomectomy and Laparoscopic Adnexectomy

\begin{tabular}{|c|c|c|c|c|}
\hline Variables & LAVH & LM & LA & $P$ value \\
\hline Age (year) & $49.0 \pm 6.8^{* \#}$ & $41.9 \pm 5.5$ & $39.1 \pm 12.1$ & $<0.001$ \\
\hline Medical Insurance Type & & & & $<0.001$ \\
\hline No & $19(7.63)$ & $30(14.29)$ & $55(26.19)$ & \\
\hline New Type Of Rural & $172(69.08)$ & $106(50.48)$ & 77 (36.67) & \\
\hline \multicolumn{5}{|l|}{ Cooperative } \\
\hline Urban Residents & $8(3.21)$ & $64(30.48)$ & $4(1.90)$ & \\
\hline Urban Workers & $50(20.08)$ & $10(4.76)$ & $74(35.24)$ & \\
\hline Education & & & & $<0.001$ \\
\hline Illiteracy & $63(25.30)$ & $20(9.52)$ & $23(10.95)$ & \\
\hline Primary School & $106(42.57)$ & $69(32.86)$ & $47(22.38)$ & \\
\hline Middle And High School & $65(26.10)$ & $88(41.90)$ & $86(40.95)$ & \\
\hline College And Higher & $15(6.02)$ & 33 (I5.7I) & $54(25.7 I)$ & \\
\hline Occupation & & & & $<0.001$ \\
\hline No & I 48 (59.44) & $75(35.7 I)$ & $72(34.29)$ & \\
\hline Yes & I0I (40.56) & 135 (64.29) & I $38(65.7 \mid)$ & \\
\hline Hypertension & & & & $<0.001$ \\
\hline No & $202(81.12)$ & $200(95.24)$ & $189(90.00)$ & \\
\hline Yes & $47(18.88)$ & $10(4.76)$ & $21(10.00)$ & \\
\hline Diabetes & & & & 0.014 \\
\hline No & $235(94.38)$ & $208(99.05)$ & $203(96.67)$ & \\
\hline Yes & $14(5.62)$ & $2(0.95)$ & $7(3.33)$ & \\
\hline A History Of Abdominal Surgery & & & & 0.075 \\
\hline No & $182(73.09)$ & $147(70.00)$ & $136(64.76)$ & \\
\hline Yes & $67(26.91)$ & $63(30.00)$ & $74(35.24)$ & \\
\hline BMI $\left(\mathrm{kg} / \mathrm{m}^{2}\right)$ & $23.56 \pm 2.88^{* \#}$ & $22.87 \pm 2.84$ & $22.57 \pm 4.06$ & $<0.001$ \\
\hline Chief Complaint & & & & $<0.001$ \\
\hline Physical Examination & $157(63.05)$ & $129(61.43)$ & I 38 (65.7I) & \\
\hline Descensus Uteri & II (4.42) & 75 (35.7I) & $29(|3.8|)$ & \\
\hline Changes In Menstruation & $60(24.10)$ & $6(2.86)$ & $43(20.48)$ & \\
\hline Dysmenorrhea & $21(8.43)$ & $0(0.00)$ & $0(0.00)$ & \\
\hline Preoperative Chronic Pain & & & & 0.002 \\
\hline No & $176(70.68)$ & $168(80.00)$ & $174(82.86)$ & \\
\hline Yes & $73(29.32)$ & $42(20.00)$ & $36(17.14)$ & \\
\hline Exercise Habit & & & & 0.185 \\
\hline No & $189(75.90)$ & $169(80.48)$ & $174(82.86)$ & \\
\hline Yes & $60(24.10)$ & $41(19.52)$ & $36(17.14)$ & \\
\hline The Level Of Anxiety & & & & $<0.001$ \\
\hline No or Mild & $182(73.09)$ & $198(94.29)$ & $20 I(95.7 I)$ & \\
\hline Moderate & $4 I(16.47)$ & $12(5.7 I)$ & 9 (4.29) & \\
\hline Severe & $26(10.44)$ & $0(0.00)$ & $0(0.00)$ & \\
\hline Pelvic Adhesions & & & & $<0.001$ \\
\hline No & $162(65.06)$ & I88 (89.52) & I 54 (73.33) & \\
\hline Yes & $87(34.94)$ & $22(10.48)$ & $56(26.67)$ & \\
\hline
\end{tabular}

(Continued) 
Table I (Continued).

\begin{tabular}{|c|c|c|c|c|}
\hline Variables & LAVH & LM & LA & $P$ value \\
\hline 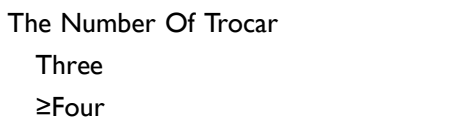 & $\begin{array}{l}\text { II } 3(45.38) \\
136(54.62)\end{array}$ & $\begin{array}{c}44(20.95) \\
166(79.05)\end{array}$ & $\begin{array}{l}5 \mathrm{I}(24.29) \\
\text { I59 (75.7I) }\end{array}$ & $<0.001$ \\
\hline $\begin{array}{l}\text { Uterine Size } \\
\text { Atrophy } \\
\text { Normal }\end{array}$ & $\begin{array}{l}31(12.45) \\
21(8.43)\end{array}$ & $\begin{array}{c}0(0.00) \\
35(16.67)\end{array}$ & $\begin{array}{l}25(11.90) \\
168(80.00)\end{array}$ & $<0.001$ \\
\hline$\leq 13$ gestational weeks & $92(36.95)$ & $96(45.7 I)$ & $17(8.10)$ & \\
\hline 13-26 gestational weeks & $105(42.17)$ & $79(37.62)$ & $0(0.00)$ & \\
\hline Bleeding volume & $20(20-50)$ & $20(20-50)$ & $10(10-20)$ & 0.247 \\
\hline Operative time & $92.02 \pm 35.25^{* \#}$ & $84.55 \pm 36.11$ & $73.75 \pm 40.94$ & 0.041 \\
\hline $\begin{array}{l}\text { Post-Operative Nausea And Vomiting } \\
\text { No } \\
\text { Only Nausea } \\
\text { Vomiting }\end{array}$ & $\begin{array}{l}169(67.87) \\
25(10.04) \\
55(22.09)\end{array}$ & $\begin{array}{l}144(68.57) \\
18(8.57) \\
48(22.86)\end{array}$ & $\begin{array}{c}161(76.67) \\
14(6.67) \\
35(16.67)\end{array}$ & 0.255 \\
\hline $\begin{array}{l}\text { Time Of Pelvic Drainage } \\
\text { I Day } \\
2 \text { Days } \\
\geq 3 \text { Days }\end{array}$ & $\begin{array}{c}193(77.5 \mathrm{I}) \\
42(16.87) \\
14(5.62)\end{array}$ & $\begin{array}{l}179(85.24) \\
20(9.52) \\
11(5.24)\end{array}$ & $\begin{array}{c}17 \mid(81.43) \\
25(11.90) \\
14(6.67)\end{array}$ & $<0.001$ \\
\hline $\begin{array}{l}\text { The Urinary Catheter Time } \\
\leq \text { I Day } \\
2 \text { Days } \\
\geq 3 \text { Days }\end{array}$ & $\begin{array}{l}40(16.06) \\
102(40.96) \\
106(42.57)\end{array}$ & $\begin{array}{c}160(76.19) \\
30(14.29) \\
20(9.52)\end{array}$ & $\begin{array}{l}180(85.7 \mathrm{I}) \\
18(8.57) \\
12(5.7 \mathrm{I})\end{array}$ & $<0.001$ \\
\hline Volume of pelvic drainage in $24 \mathrm{~h}$ & $80(50-145)$ & $100(40-170)$ & $60(0-150)$ & $<0.001$ \\
\hline
\end{tabular}

Notes: Data were presented as $\mathrm{n}(\%)$ or mean \pm standard deviation. ${ }^{*} \mathrm{P}<0.05$ compared with LA; ${ }^{*} \mathrm{P}<0.05$ compared with LM.

Table 2 Incidence of Different Types of Postoperative Pain of Laparoscope-Assisted Vaginal Hysterectomy

\begin{tabular}{|l|l|l|l|l|l|}
\hline Type of Pain & No (n, \%) & Mild (n, \%) & Moderate (n, \%) & Severe (n, \%) & Mean \\
\hline Visceral pain & $26(10.4)$ & $110(44.2)$ & $64(25.7)$ & $49(19.7)$ & 3.77 \\
Incision pain & $74(29.7)$ & $116(46.6)$ & $53(21.3)$ & $6(2.4)$ & $36(14.5)$ \\
Low back pain & $61(24.5)$ & $99(39.8)$ & $53(21.3)$ & $7(2.8)$ & 3.06 \\
Shoulder pain & 2II (84.7) & $26(10.4)$ & $5(2.0)$ & 0.55 \\
\hline
\end{tabular}

Note: Values were presented as $\mathrm{n}(\%)$.

Table 3 Incidence of the Moderate to Severe Pain Following Laparoscope-Assisted Vaginal Hysterectomy

\begin{tabular}{|l|c|c|}
\hline & Number & Incidence (\%) \\
\hline 0 type of moderate to severe pain & 67 & 26.9 \\
I type of moderate to severe pain & 105 & 42.2 \\
2 types of moderate to severe pain & 65 & 26.1 \\
3 types of moderate to severe pain & 10 & 4.0 \\
4 types of moderate to severe pain & 2 & 0.8 \\
\hline
\end{tabular}

Notes: The 4 types of pain were: visceral pain, incisional pain, low back pain, shoulder pain. baseline characteristics were found to influence postoperative pain. ${ }^{16-20}$ Pelvic adhesions were also important factors affecting postoperative pain, and patients with them were susceptible to postoperative pain. ${ }^{21}$ Similarly, there were significant differences in the number of intraoperative trocars and the durations of surgery for the three groups. There were significant differences in the variables such as postoperative pelvic drainage time, indwelling catheter time, and 24-h pelvic drainage in the three groups. 
Table 4 Incidence of Different Types of Postoperative Pain of Laparoscopic Myomectomy

\begin{tabular}{|l|l|l|l|l|l|}
\hline Type of Pain & No (n, \%) & Mild (n, \%) & Moderate (n, \%) & Severe (n, \%) & Mean \\
\hline Visceral pain & $48(22.9)$ & $76(36.2)$ & $46(21.9)$ & $40(19.0)$ & $9(4.3)$ \\
Incision pain & $49(23.3)$ & $129(61.4)$ & $23(11.0)$ & $23(11.0)$ & 2.22 \\
Low back pain & $84(40.0)$ & $70(33.3)$ & $33(15.7)$ & $2(1.0)$ & 2.40 \\
Shoulder pain & $162(77.1)$ & $31(14.8)$ & $15(7.1)$ & 0.74 \\
\hline
\end{tabular}

Note: Values were presented as $\mathrm{n}(\%)$.

Table 5 Incidence of the Moderate to Severe Pain Following Laparoscopic Myomectomy

\begin{tabular}{|l|c|c|}
\hline & Number & Incidence (\%) \\
\hline 0 type of moderate to severe pain & 82 & 39.0 \\
I type of moderate to severe pain & 75 & 35.7 \\
2 types of moderate to severe pain & 44 & 21.0 \\
3 types of moderate to severe pain & 8 & 3.8 \\
4 types of moderate to severe pain & 1 & 0.5 \\
\hline
\end{tabular}

Note: The 4 types of pain were: visceral pain, incisional pain, low back pain, shoulder pain.

The differences between these intraoperative and postoperative variables also affected the difference in postoperative pain.

An increase in the number of trocars was accompanied by an increase in injuries, which increased postoperative pain. However, laparoscopic surgery with a smaller number of trocars required less space for operation and higher requirements for the doctor, and the intraoperative time may be longer. It is more likely to cause injury, and the possibility of postoperative pain will increase. Therefore, the relationship between the number of trocars and postoperative pain was still controversial. The larger number of trocars was a protective factor for low back pain, which may be related to reduce the operation time. ${ }^{22-24}$

Comparison of the characteristics and incidence of postoperative pain in the LAVH, LM, and LA groups showed that visceral pain and low back pain were the most common forms of postoperative pain in the LAVH and LM groups; however, incisional pain was the most common postoperative pain in the LA group, but the pain score was lower. The LAVH group had the highest severity, followed by the LM and LA groups, indicating that the severity of postoperative pain was related to the size of surgical trauma, ${ }^{25}$ but at the same time, the severity and incidence of postoperative pain in the LM and LA groups cannot be ignored. We also cannot take the postoperative analgesia of short surgery lightly. ${ }^{9}$ The use of analgesics in the three groups was relatively frequent and was related to the most severe postoperative pain in the LAVH group, but there was no significant difference in the use by the LM and LA groups, indicating that postoperative pain in the LM group, which is more severe, has not received enough attention. The dose of remifentanil administered during surgery was not included in the statistics in this study because of the short half-life of remifentanil; the results of this study suggest that the same gynaecological laparoscopic in the LAVH, LM, and LA groups can be associated with postoperative pain with significantly different manifestations, incidence, and severities.

According to previous studies, visceral pain may be related to insufficiency of the dose of opioids or the nonadministration of NSAIDs. For these patients, it is necessary to increase the use of opioids and NSAIDs. ${ }^{26}$ Due to the side effects of opioids, in patients with preoperative risk factors, the opioid prescriptions can be personalised to help reduce excessive opioid intake, ${ }^{27}$ and low-dose spinal analgesia combined with general anaesthesia can also be considered to reduce the perioperative opioid dosage immediately after gynaecological surgery. ${ }^{28}$ Previous studies have reported that low back pain

Table 6 Incidence of Different Types of Postoperative Pain of Laparoscopic Adnexectomy

\begin{tabular}{|c|c|c|c|c|c|}
\hline Type of Pain & No (n, \%) & Mild (n, \%) & Moderate (n, \%) & Severe $(n, \%)$ & Mean \\
\hline Visceral pain & $104(49.5)$ & 7I (33.8) & $26(12.4)$ & $9(4.3)$ & 1.64 \\
\hline Incision pain & $4 I(19.5)$ & $145(69.0)$ & $24(1 \mathrm{I} .4)$ & $0(0)$ & 2.21 \\
\hline Low back pain & $130(6 \mid .9)$ & $47(22.4)$ & $30(14.3)$ & $3(1.4)$ & 1.27 \\
\hline Shoulder pain & $164(78.1)$ & 30 & $16(7.6)$ & $0(0)$ & 0.70 \\
\hline
\end{tabular}

Note: Values were presented as $\mathrm{n}(\%)$. 
Table 7 Incidence of the Moderate to Severe Pain Following Laparoscopic Adnexectomy

\begin{tabular}{|l|c|c|}
\hline & Number & Incidence (\%) \\
\hline 0 type of moderate to severe pain & 128 & 61.0 \\
I type of moderate to severe pain & 59 & 28.1 \\
2 types of moderate to severe pain & 20 & 9.5 \\
3 types of moderate to severe pain & 3 & 1.4 \\
4 types of moderate to severe pain & 0 & 0.0 \\
\hline
\end{tabular}

Notes: The 4 types of pain were: visceral pain, incisional pain, low back pain, shoulder pain. assessed at the same time after the operation. We only knew the maximum pain of the patients within 2 days, and we did not follow up and investigate the patients for a longer period of time. The study did not carry out further in-depth discussion and analysis of its mechanism of postoperative pain, which was also a shortcoming. The study only compared LAVH, LM, and LA as forms of gynaecological laparoscopic surgery, we can further study the postoperative pain of other operations.

Table 8 Comparison Between Laparoscope-Assisted Vaginal Hysterectomy, Laparoscopic Myomectomy and Laparoscopic Adnexectomy

\begin{tabular}{|c|c|c|c|c|c|}
\hline & LA & LM & LAVH & $\mathbf{F}$ & $\mathbf{P}$ \\
\hline 0 type of moderate to severe pain & $128(61 \%)$ & 82 (39\%) & $67(26.9 \%)$ & 55.13 & $<0.001$ \\
\hline At least I type of moderate to severe pain & $82(39 \%)$ & $128(61 \%)$ & $182(73.1)$ & 55.13 & $<0.001$ \\
\hline Highest pain scores during the $48 \mathrm{~h}$ after surgery & $3.45(1.77)$ & $4.69(2.4 \mathrm{I})$ & $5.03(2.4 I)^{* \#}$ & 30.09 & $<0.001$ \\
\hline Opioid consumption during surgery (mg) & II.28 (2.02) & $11.43(1.42)$ & $\mathrm{II} .78(\mathrm{I} .43)^{*}$ & 5.58 & 0.004 \\
\hline The number of opioid users in the PACU & II (5.2\%) & $23(11 \%)$ & 31 (12.4\%) & 7.29 & 0.03 \\
\hline The number of indomethacin users & $69(32.9 \%)$ & $23(11 \%)$ & 95 (38.2\%) & 45.5 & $<0.001$ \\
\hline The number of pethidine users & $2(1.0 \%)$ & $0(0 \%)$ & $12(4.8 \%)$ & 14.86 & $<0.001$ \\
\hline The total consumption of opioids (mg) & $|1.5|(2.32)$ & $11.80(1.85)$ & $|2.4|(2.43)^{*}$ & 9.83 & $<0.001$ \\
\hline
\end{tabular}

Notes: Data were presented as $\mathrm{n}(\%)$ or mean \pm standard deviation. ${ }^{*} \mathrm{P}<0.05$ compared with LA; ${ }^{*} \mathrm{P}<0.05$ compared with LM.

may be related to preoperative anxiety, duration of surgery, and longer lying time after surgery in patients undergoing LAVH. For these patients, it was necessary to reduce the lying time during the perioperative period and consider anti-anxiety interventions. ${ }^{29}$ For patients with incision pain as the main cause, the effect of local anaesthesia may be poor, ${ }^{30}$ and it will be necessary to increase the dose of regional block local anaesthetics, improve regional block technology, and use NSAIDs in combination. It is possible that postoperative incision pain in these surgical patients can be effectively controlled. ${ }^{31}$ At the same time, regional blocks can also have a therapeutic effect on visceral pain. ${ }^{32}$ It was more beneficial for patients with severe shoulder pain to have shorter durations of surgery, reduced head down and toe height times, and reduced intraoperative abdominal pressure. ${ }^{33}$ Changes in surgical methods can also affected postoperative pain in patients. ${ }^{23,24}$ In summary, actively adopt low-opioid, multimodal, preventive, and individualized analgesia programs can achieve the largest analgesic effect, the smallest adverse reactions, the best physical and psychological functions, the best quality of life and patient satisfaction.

The patients were interviewed at 17:00 on the first day and the second day. But actually, the pain should be

\section{Conclusion}

The characteristics of acute postoperative pain were different in LAVH, LM and LA. The LAVH group had the highest incidence and the most severe postoperative pain, followed by the LM group and the LA group. The acute postoperative pain in LAVH and LM groups was mainly visceral pain and low back pain, and the LA group was mainly incisional pain. We should clinically adjust the analgesic plan according to the different surgeries.

\section{Data Sharing Statement}

The clinical data used to support the findings of this study are available from the corresponding author upon reasonable request.

\section{Acknowledgments}

This work was supported by National Foundation of Natural Science of China (No.81803937, No.81603685 and No.81573742), Natural Science Foundation of Zhejiang Province (CN) (No. LY15H290006, No. LY19H290008) and Wenzhou Municipal Science and Technology Bureau (CN) (2018ZY003). 


\section{Disclosure}

The authors report no conflicts of interest in this work.

\section{References}

1. Schug SA. 2011-the global year against acute pain. Anaesth Intensive Care. 2011;39(1):11-14. doi:10.1177/0310057X1103900102

2. Joo J, Moon HK, Moon YE. Identification of predictors for acute postoperative pain after gynecological laparoscopy (STROBE-compliant article). Medicine (Baltimore). 2019;98(42): e17621. doi:10.1097/MD.0000000000017621

3. Ekstein P, Szold A, Sagie B, Werbin N, Klausner JM, Weinbroum AA. Laparoscopic surgery may be associated with severe pain and high analgesia requirements in the immediate postoperative period. Ann Surg. 2006;243(1):41-46. doi:10.1097/01.sla.0000193806.81428.6f

4. Scheel J, Sittl R, Griessinger N, et al. Psychological predictors of acute postoperative pain after hysterectomy for benign causes. Clin J Pain. 2017;33(7):595-603. doi:10.1097/AJP.0000000000000442

5. Pinto PR, McIntyre T, Almeida A, Araújo-Soares V. The mediating role of pain catastrophizing in the relationship between presurgical anxiety and acute postsurgical pain after hysterectomy. Pain. 2012;153(1):218-226. doi:10.1016/j.pain.2011.10.020

6. Frot M, Feine JS, Bushnell CM. Sex differences in pain perception and anxiety. A psychophysical study with topical capsaicin. Pain 2004;108(3):230-236. doi:10.1016/j.pain.2003.11.017

7. Fillingim RB, Maixner W, Kincaid S, Silva S. Sex differences in temporal summation but not sensory-discriminative processing of thermal pain. Pain. 1998;75(1):121-127. doi:10.1016/S03043959(97)00214-5

8. Salazar-Parra M, Guzman-Ramirez BG, Pintor-Belmontes KJ, et al. Gender differences in postoperative pain, nausea and vomiting after elective laparoscopic cholecystectomy. World J Surg. 2020;44 (12):4070-4076. doi:10.1007/s00268-020-05744-3

9. Gerbershagen HJ, Aduckathil S, van Wijck AJ, Peelen LM, Kalkman CJ, Meissner W. Pain intensity on the first day after surgery: a prospective cohort study comparing 179 surgical procedures. Anesthesiology. 2013;118(4):934-944. doi:10.1097/ALN.0b013 e31828866b3

10. Joshi GP, Van de Velde M, Kehlet H; PROSPECT Working Group Collaborators. Development of evidence-based recommendations for procedure-specific pain management: PROSPECT methodology. Anaesthesia. 2019;74(10):1298-1304. doi:10.1111/anae.14776

11. Choi JB, Kang K, Song MK, Seok S, Kim YH, Kim JE. Pain characteristics after total laparoscopic hysterectomy. Int J Med Sci. 2016;13(8):562-568. doi:10.7150/ijms.15875

12. Chen SJ, Du WW, Mo YC, Wang JL, Huang L. Risk factors of different types of acute pain after laparoscope-assisted vaginal hysterectomy. Signa Vitae. 2021;17(2):193-207.

13. Johansen A, Romundstad L, Nielsen CS, Schirmer H, Stubhaug A. Persistent postsurgical pain in a general population: prevalence and predictors in the Tromsø study. Pain. 2012;153(7):1390-1396. doi:10.1016/j.pain.2012.02.018

14. Bisgaard T, Klarskov B, Rosenberg J, Kehlet H. Characteristics and prediction of early pain after laparoscopic cholecystectomy. Pain. 2001;90(3):261-269. doi:10.1016/S0304-3959(00)00406-1

15. Ruscheweyh R, Viehoff A, Tio J, Pogatzki-Zahn EM. Psychophysical and psychological predictors of acute pain after breast surgery differ in patients with and without pre-existing chronic pain. Pain. 2017;158(6):1030-1038. doi:10.1097/j.pain.0000000000000873

16. Sommer M, de Rijke JM, van Kleef M, et al. Predictors of acute postoperative pain after elective surgery. Clin J Pain. 2010;26 (2):87-94. doi:10.1097/AJP.0b013e3181b43d68

17. Pinto PR, Vieira A, Pereira D, Almeida A. Predictors of acute postsurgical pain after inguinal hernioplasty. J Pain. 2017;18(8):947-955. doi:10.1016/j.jpain.2017.03.003
18. Pinto PR, McIntyre T, Nogueira-Silva C, Almeida A, Araújo-Soares $\mathrm{V}$. Risk factors for persistent postsurgical pain in women undergoing hysterectomy due to benign causes: a prospective predictive study. J Pain. 2012;13(11):1045-1057. doi:10.1016/j.jpain.2012.07.014

19. Brandsborg B. Pain following hysterectomy: epidemiological and clinical aspects. Dan Med J. 2012;59(1):B4374.

20. Pinto PR, McIntyre T, Almeida A, Araújo-Soares V. Understanding pre-surgical predictors of acute pain experience following hysterectomy for benign causes: conceptual and methodological issues. Pain. 2012;153(9):1974-1976. doi:10.1016/j.pain.2012.05.022

21. Ortner CM, Granot M, Richebé P, Cardoso M, Bollag L, Landau R. Preoperative scar hyperalgesia is associated with post-operative pain in women undergoing a repeat Caesarean delivery. Eur J Pain. 2013;17(1):111-123. doi:10.1002/j.1532-2149.2012.00171.x

22. Chung JH, Baek JM, Chung K, et al. A comparison of postoperative pain after transumbilical single-port access and conventional three-port total laparoscopic hysterectomy: a randomized controlled trial. Acta Obstet Gynecol Scand. 2015;94(12):1290-1296. doi:10.1111/aogs.12767

23. Kaya C, Alay I, Cengiz H, Yıldız GO, Baghaki HS, Yasar L. Comparison of hysterectomy cases performed via conventional laparoscopy or vaginally assisted natural orifice transluminal endoscopic surgery: a paired sample cross-sectional study. J Obstet Gynaecol. 2021;41(3):434-438. doi:10.1080/01443615.2020.1741523

24. Kaya C, Yıldız Ş, Alay İ, Aslan Ö, Aydıner İE, Yaşar L. The comparison of surgical outcomes following laparoscopic hysterectomy and vNOTES hysterectomy in obese patients. $J$ Invest Surg. 2021;1-6. doi:10.1080/08941939.2021.1927262

25. Kliethermes C, Blazek K, Ali K, Nijjar JB, Kliethermes S, Guan X. Postoperative pain after single-site versus multiport hysterectomy. JSLS. 2017;21(4):e2017.00065. doi:10.4293/JSLS.2017.00065

26. Wong M, Morris S, Wang K, Simpson K. Managing postoperative pain after minimally invasive gynecologic surgery in the era of the opioid epidemic. J Minim Invasive Gynecol. 2018;25(7):1165-1178. doi:10.1016/j.jmig.2017.09.016

27. Wong M, Vogell A, Wright K, Isaacson K, Loring M, Morris S. Opioid use after laparoscopic hysterectomy: prescriptions, patient use, and a predictive calculator. Am J Obstet Gynecol. 2019;220 (3):259.e1-259.e11. doi:10.1016/j.ajog.2018.10.022

28. Zdravkovic M, Kamenik M. A prospective randomized controlled study of combined spinal-general anesthesia vs. general anesthesia for laparoscopic gynecological surgery: opioid sparing properties. J Clin Anesth. 2020;64:109808. doi:10.1016/j.jclinane.2020.109808

29. Borges NC, Pereira LV, de Moura LA, Silva TC, Pedroso CF. Predictors for moderate to severe acute postoperative pain after cesarean section. Pain Res Manag. 2016;2016:5783817. doi:10.1155/2016/5783817

30. Levene JL, Weinstein EJ, Cohen MS, et al. Local anesthetics and regional anesthesia versus conventional analgesia for preventing persistent postoperative pain in adults and children: a Cochrane systematic review and meta-analysis update. J Clin Anesth. 2019;55:116-127. doi:10.1016/j.jclinane.2018.12.043

31. Liang HS, Feng Y, Liu YZ, An HY, Yang BX. [Effect of flurbiprofen combined different concentrations of ropivacaine local infiltration on postoperative analgesia after laparoscopic cholecystectomy]. Beijing Da Хие Хие Bao Yi Xиe Ban. 2011;43(5):753-756. Chinese.

32. Ishio J, Komasawa $\mathrm{N}$, Kido $\mathrm{H}$, Minami T. Evaluation of ultrasound-guided posterior quadratus lumborum block for postoperative analgesia after laparoscopic gynecologic surgery. J Clin Anesth. 2017;41:1-4. doi:10.1016/j.jclinane.2017.05.015

33. Kandil TS, El Hefnawy E. Shoulder pain following laparoscopic cholecystectomy: factors affecting the incidence and severity. $J$ Laparoendosc Adv Surg Tech A. 2010;20(8):677-682. doi:10.1089/lap.2010.0112 
Journal of Pain Research

Dovepress

\section{Publish your work in this journal}

The Journal of Pain Research is an international, peer reviewed, open access, online journal that welcomes laboratory and clinical findings in the fields of pain research and the prevention and management of pain. Original research, reviews, symposium reports, hypothesis formation and commentaries are all considered for publication. The manuscript management system is completely online and includes a very quick and fair peer-review system, which is all easy to use. Visit http:// www.dovepress.com/testimonials.php to read real quotes from published authors.

Submit your manuscript here: https://www.dovepress.com/journal-of-pain-research-journal 